\title{
The Fashion-Architecture's Theory: Reflecting Tribe Civilization into Contemporary Age
}

\author{
Yuke Ardhiati \\ Department of Architecture of Engineering Faculty, Pancasila University, Jakarta 12640, Indonesia
}

\begin{abstract}
In megacities, the phenomenon of the highrise buildings which add fashion elements into the body and facades seems as big sculptures. Architect composed their work by applying the cross-pollination of design method. They adopted the various elements to enrich their building's façade in order to look different. On the other hand, the traditional architecture expressed the tribe civilization by placing their proud artifacts into the building's façade. The purpose of this study is to find a new theory of architecture during their process of becoming of the architecture's form. The study applied a phenomenological investigation method of several highrise building's façade at Jakarta and several districts of Singapore, Brisbane and Melbourne. The study result is a new theory named "the fashion-architecture” is a building composed by adopting the cross-pollination of design method. To enrich the building's façade, architect adopted anything including the fashion's design elements: accessories, millineries, and cosmetics also reflected by the traditional architecture. Their fashion-architecture works are reflecting the tribe civilization into a contemporary architecture design.
\end{abstract}

Key words: Cross-pollination, façade fashion's design elements, contemporary, tribe civilization.

\section{Introduction}

Fashion-architecture is a new phenomenon in architecture terms. They can reflect a metaphorical building by reflecting the fashion design elements into their building's form especially on their façades. They compose the buildings by adopting the fashion elements: accessories, millineries and cosmetics to enrich their building performance, and applying the four principles of design: color, silhouette, line and texture into the architecture's body. To enrich the building's design, architects insert various fashion design methods by wrapping, pleating, printing, draping, folding and weaving. By inserting them into the buildings, "form” and façades are composing a unique, fun and extraordinary building. So, visually they seem unusual building's appearances even when they are similar as a big statue or sculpture in the city. When a building was added with fashion elements, its appearance becomes "a supermodel". In several cases, a building added the fashion accessories to contribute

Corresponding author: Yuke Ardhiati, Dr., research fields: architecture, building conservation, theory and creative design. E-mail: yuke_ardhiati@yahoo.com. a secondary manner to make the building's outfit. Sometimes, the building needs related "cosmetics" to enhance the appearance or odor of the body of the building. Finally, sometimes a building needs "millineries", as the art and trade of designing to make the building's hats, etc.. After adding something to the building appearance's by parametric design to create the uniqueness of "form", the building becomes a new iconic building. Recently, the fashion-architecture is built in several megacities such as Hadid, Tschumi and Gehry's masterpieces. Besides Singapore, Brisbane and Melbourne, the unusual buildings also locate at several districts at capital city of Jakarta. The unique phenomenon has been encouraged to purpose the process of becoming the architecture's "form".

A "wow effect" in architecture perform is introduced by Derrida [1]. He stated about trans-architecture, architecture-event or maintenance-architecture concepts by creating: séquence, sérialitéouverte, narrativité, cinématique, dramaturgie, chorégraphieto (sequence, open seriality, narrative, cinematic, dramatic and choreographic features), a pleasant architecture or architecture's event presented by Zaha 
Hadid, Bernard Tshcumi, which is reflected in several fashion-architecture buildings. The same architecture phenomenon is built in megacities Jakarta in 1988. The unusual building's appearances seem as a big statue or sculpture in the cities which, in their creative process, apply the cross-pollination method to compose their architectural appearance.

When the architect adopted the fashion elements: accessories, millineries and cosmetics, and the four principles of design: color, silhouette, line, and texture into the architecture's body, the building's appearance became metaphorical fashion named "fashion-architecture" building by Ardhiati [2]. By placing the details with the fashion elements, they look like unusual building's appearances even if they are similar as a big statue or sculpture.

The discussion about the connections between fashion and architecture were started by Skin+Bones [3]. First, they exposed the parallel practices in fashion and architecture when they explored the advances in materials technology and computer software to push the frontiers of each discipline. Buildings become more fluid in architecture's "form" and garments more architectonic in cloth's style. Architects are adopting strategies more usually used in dressmaking, such as printing, pleating, folding, draping and weaving, while fashion designers are looking for ways to build in architecture or engineer garments which present new and provocative ideas about volume and structure.

Architects also draw on the intellectual principles and concepts inherent in architecture in order to make the new building's appearance. Before it's appearance, Tschumi [4] has introduced the "Event-Cities" project.

The fashion-architecture is an entertainment in the selected communities and art performing's genre. Skin+Bones [3] introduced a cross-pollination method and influences between both architecture and fashion. In Britain, the appearance is known as FAT-fashion architecture taste. Referring to Skin+Bones [3], the texture method of fashion design principles to enrich the building façade is created by wrapping, pleating, printing, draping, folding and weaving.

By wrapping, architects use new materials and digital technology to redefine what the relationship is between the framework and façade. By pleating, fold technique has been widely used by fashion designer and is often applied to bring unusual shape and strengthen the impression of volume. However, in architecture, pleat effects are used to soften the impression of a monolithic building and even give a visual impression of immaterial light. Texture generates a pseudo prink on fabric and will create a certain impression depending on visual effect when applied to clothing, in the building application, as something wrapped or sown with line, color combination as the ornament of object. Folding and draping fabric impress a typical fashion repertoire. Folded cloth gives the soft impression. The overlapping effects of pleated fabric, used also by the architect, use digital technology to create a new form with very complicated and complex details. By folding, architect creates a dramatic of the visual effects.

Referring to Colomina [5], the human body is not only apprehended as subject who experiences space, but also as a site and a landscape for designing human's most intimate space, which is fashion. In architecture, designer needs to negotiate with social, tectonic and structural realm where architecture meets fashion.

Hadid is also role architects who introduced new ways of thinking into the universe of fashion. "There is a lot of fluidity now between art, design and architecture- $\mathrm{a}$ lot more cross-pollination in the disciplines," she says, "It is essential to find key collaborators to work on new discoveries and push them into the mainstream.”

Referring to Prawoto [6], the cross-pollination of design strategy is used by architects as embodiment of fashion and also making techniques, while designers use the architecture's methods such as cantilever and suspension engineering in construction using a sign or membrane. It is widely used in the architecture to create a dynamic and dramatic impression with a point 
or sharp corner while in fashion it is used to give shape and firmness or the structure of the clothing's construction.

While in fashion as a processing method, in architectural techniques such as webbing, knitted connection also encounters a variety of materials.

Cantilever is used in engineering and architecture repertoire is used in the fashion for articulating surfaces, manipulating volumetric and also giving rise to a dramatic silhouette. Suspension is adopted to realize the view held by fabric sling hanging rows of yarn such as the construction of a suspension bridge as the interplay between fashion looks premises architecture which opens up a new horizons creations. The expression "form" of architectural tectonics becomes a new frontier for explorations with various form processing.

Weaving technique to create woven textiles has been adopted by architecture to connect or assemble the spatial volume of the building and interior space that interrelated in processing the application surface.

Different kinds of material can also apply to regarding as a process of stringing or weaving.

Referring to Hedayat [7], this design strategy is different from the "form processing", but allow more flexible architecture to organize space, technology, and aesthetics is certainly different spirit and honesty in expressing and becomes important as integrity, unity with the idea of embodiment space.

\section{Method}

The study is aiming at finding a new theory in architecture based on the building façades and investigating the architecture phenomenon by referring to grounded theory research method of Strauss [8] as a part of qualitative research of Groat [9]. The observation method is referred by visual experiences, the uniqueness of the building's quality and "form", and by revealing khora which is the Greece term to describe the proses becoming as architecture's "form" through an interpretation. The visual experiences of
Rose [10] by using a phenomenology strategy investigation refer to Tjahjono [11] in the spatial experiences along Jakarta's main axis corridor at SCBD (Sudirman Central Business District), Rasuna Said-Setiabudi and Casablanca and visit to several megacities such as Singapore, Brisbane and Melbourne. The results are a new theory by directing the "topic guide" of data with comparing incidents applicable to each category, integrating categories and their properties, delimiting the theory and writing theory of Strauss [8].

\section{Findings}

Buildings is the phenomenon of the fashion-architecture found at Setiabudi-Rasuna Said district of Jakarta (Fig. 1). The two towers of MD Place Tower (Fig. 2) which belong to MD Corp group by Manoj Punjabi are unique architecture "forms" in a high-tech building as a new icon amongst the Jakarta skyline. By resembling a spider's web, the view outside seems like a spider building. The building philosophy of form is based on the organic form, constantly growing and evolving, and is similar to the company mission purpose to develop the world of soap operas and film in Indonesia. Architect uses the cross-pollination method in order to build form of MD

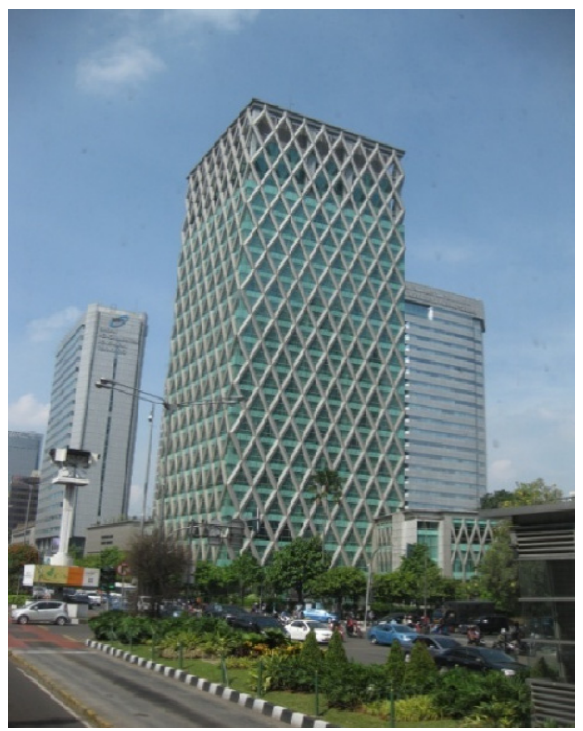

Fig. 1 The Jakarta's fashion-architecture.

Source: the author, 2014. 


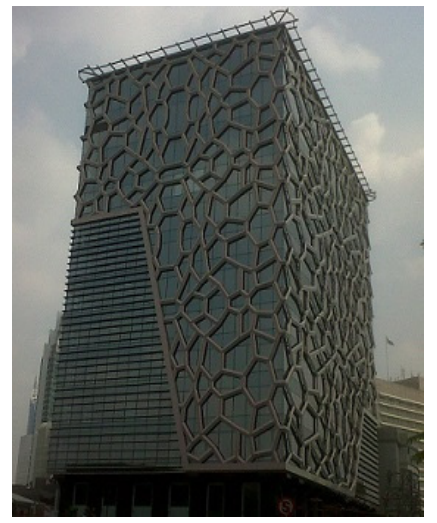

Fig. 2 The LED of MD Entertainment Building, Jakarta. Source: www.mdentertainment.co.

Place Tower into a "fashion-architecture" style. Architect applied the modernist approach, practical, and powerfully simple, and inserted the building façade by placing the details with fashion elements: accessories, millineries and cosmetics. The building façades are added with the fashion accessories by using the LED lighting with a spider pattern as a secondary manner to make the building's outfit.

To enrich the perform, the LED lightings are used in the building facades with some fashion accessories and spider pattern as a secondary manner to make the building's outfit. The building is using the artwork to cover all of the body. Overall, the building's appearance becomes a "supermodel" or an actress in the night. Other fashion-architectures are found around the Sudirman Central Business District's area. The building's façades are enriched by covering various materials as their cloths. The uniqueness styles of buildings are becoming the new iconic buildings. The appearances are showing unusual building façades. They adopted the four basics of fashion elements and principles of design: color, silhouette, line and texture into the architecture's body and facades. By adopting the fashion elements, the buildings are becoming a metaphoric in fashion-architecture placing the fashion elements: accessories, millineries and cosmetics. To sum up, they look like the unusual building's appearances even when they are similar as a big statue or sculpture in the city.

The architects applied the cross-pollination method to compose the fashion-architecture to express the contemporary architecture's concept of Derrida: Le Maintenance-Architecture by séquence, sérialitéouverte, narrativité, cinématique, dramaturgie, chorégraphieto (sequence, open seriality, narrative, cinematic, dramatic and choreographic) become a pleasure of fashion-architecture. The ways of thinking about architecture and fashion reveal the potential that can be gained from an increasingly fruitful dialogue between these two creative disciplines. New generations of architect/designers in both fields are poised to develop ever more ingenious ways of adapting and adopting each other's forms and strategies to transform the very nature of buildings and clothes.

The architects are also using the cross-pollination method to make the "MD Place Towers 1 and 2" become a "fashion-architecture" by approaching the modernist, practical and powerfully simple, and inserting the building façades by placing the details with the fashion's elements: accessories, millineries and cosmetics. The MD Place Towers 1 and 2 buildings added with the fashion element in the building appearance are becoming iconic buildings in this district. The building façades are added with the fashion accessories by using the LED lightings with a spider pattern as a secondary manner to make the building's outfit. The building is using the artwork to cover all parts of the body. Therefore, the building's appearance becomes a "supermodel" or an actress at night. Other fashion-architecture of equity building located at Sudirman Central Business District's area. The building is also covering with a fantastic cloth in a geometrical diamond pattern by LED in gold nuance.

\section{Results}

In fact, the tribe civilization phenomenon of Indonesian reflected by the traditional architectures locates in many islands. The building typology is reflected the microcosmos and divided into three parts 
of building: head within and without the crown, the body and the pedestal. The several traditional architecture of Karo, Rumah Gadang, Joglo, Tongkonan (Fig. 3) and Wantilan which include something monad of Indonesia is the resources of inspire as the basic design. It is found various architecture, ornamental is applied in any, that looks like the sacred cloth and placed in architecture traditional elements. They enrich the next of architecture's
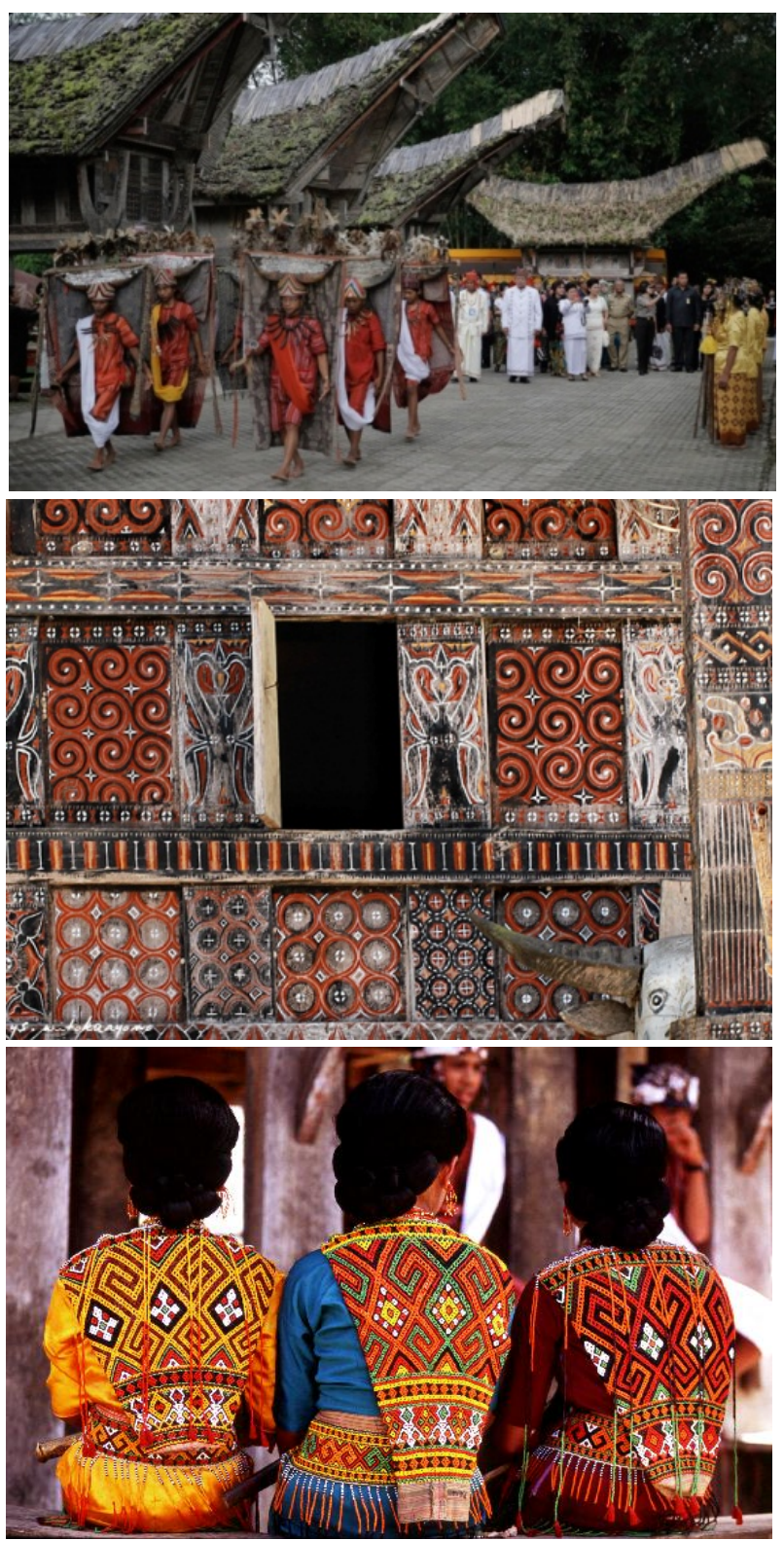

Fig. 3 The fashion-architecture of Tongkonan which in integrated between architecture and their fashion clothes. Source: www.banggaindonesia.com. facades. The ancient Indonesian architect named Wastuwidyawan had added the content of culture into the traditional architecture such as the elements of the sacred cloth, symbol, myth which were carved to create the "form". It's embedded in thus building named the Indonesian Monad as the soul of art in traditional architecture of Nusantara (Indonesia).

The elements of the sacred cloth are coloring into the building composed. The fashion's cloth elements became a visual language in the traditional architecture. Because they composed the buildings by adopting the basic fashion elements: accessories, millineries, and cosmetics to enrich their building perform, and also adopting the principles of design: color, silhouette, line, and texture into the architecture's body, so the traditional architecture of Indonesia is similar to the fashion-architecture phenomenon in contemporary age.

By using visual investigation at several districts of the eastern Indonesia, the fashion-architecture phenomenon in Papua/Irian Jaya was found. They applied the same material to beautify her/his body and face which is also used to build their houses. The also applied the natural cosmetic from the earth material into his/her face in mystical pattern. The harmony between their clothes and building house by plaiting the palm fiber, the applied natural earth color-black, red of blood and white of bone are used as the house ornaments. The geometric mystic patterns of their body, face and totem show the originality of their handmade. The Betang House of Dayak of Kalimantan is also named balai or lamin. Their building house is also harmonious within their fashion elements: accessories, millineries, and cosmetics in a geometrical pattern which is absolutely different with Papua. The Dayak's beautification is always performed by their cultural pattern in black color as the background.

Referring to the analysis, architect of Indonesian's Tribe had inserted the cultural content the into architecture design in harmony with their sacred cloth, symbol, myth, carved and totem in the tribe civilization which is in appearance into the fashion-architecture by 
inserting the fashion elements into the façades and the "form" that are beyond the architecture's convention. A new theory of the fashion-architecture refers to the Indonesian traditional architecture of Papua's House, Tongkonan, RumahGadang, Joglo, and Wantilan as role of the inspiring resources to architects to create the architecture's "form".

\section{Conclusions}

"Fashion-architecture" building is the uniqueness style of buildings form as a new icon in skyline. Their appearances are showing unusual building façades by adopting the four basic principles of design: color, silhouette, line, and texture into the architecture's body and facades and adopting the fashion elements: accessories, millineries and cosmetics. By adopting all of those elements into the architecture's body and facades, the buildings' appearances became a metaphorically building similar as a big statue or sculpture. The metaphorical building is reflected by the integrated element of traditional architecture with the traditional clothes.

The fashion-architecture is found as a new theory to create a new buildings icon by applying the cross-pollination method inspired by the tribe civilization Indonesian to express the contemporary architecture's concept by exploring the Derrida's concepts of trans-architecture, and by applying sequence, open seriality, narrative, cinematic, dramatic and choreographic.

The fashion-architecture theory of architecture is a role to enrich the various architecture's form and facades to increasingly dialogue between two creative disciplines of architect and fashion designer.
The new generations of architects/designers in both fields are poised to develop ever more ingenious ways of adapting and adopting each other's forms and strategies to transform the very nature of buildings and clothes.

\section{References}

[1] J. Derrida, Point de Folie-Maintenant L' Architecture (Point of Madness-Maintenant L' Architechture) [Online], 2009, http://www.jacquesderrida.com.ar/Point de folie-maintenant l'architecture_source (accessed Apr. 27, 2009). (in French)

[2] Y. Ardhiati, The Jakarta's fashion-architecture, in: Proceeding of Seminar Architecture Design Art + Engineer of Pancasila University, Jakarta, 2014, p. 55.

[3] Skin+Bones, Parallel Practices in Fashion and Architecture [Online], 2007, http://www.thecityreview. com/skinb.htm (accessed Dec. 14, 2011).

[4] B. Tschumi, Event-Cities (Praxis), The MIT Press, London, 1999.

[5] B. Colomina, Collaborations: The private life of modern architecture, Journal of the Society of Architectural Historians Architectural History 58 (3) (1999) 462-471.

[6] E. Prawoto, The Tectonics Aesthetics of Architecture and Fashion as an Embodying Strategy of Design, Taman Budaya, Yogyakarta, 2009.

[7] A. Hedayat, Inquiry on interrelationships between architecture and fashion design, M.Sc. Thesis, Architecture Eastern Mediterranean University, 2012.

[8] A. Strauss, Basics of Qualitative Research, Grounded Theory Procedures and Techniques, Sage Publications, Cambridge, 1990.

[9] L. Groat, D. Wang, The Architectural Research Methods, John Wiley \& Sons Inc., Canada, 2002.

[10] G. Rose, Visual Methodologies: An Introduction to the Interpretation of Visual Materials, Sage Publications Ltd, London, 2006.

[11] G. Tjahjono, Design Method: The Introduction to Architect and Designer, Department of Architecture of University of Indonesia, Jakarta, 1999. 